\title{
Comparison of Power Output from Solar Panel with Reflector and without Reflector
}

\author{
Thet Naung Win \\ Department of Electrical Power Engineering \\ Mandalay Technological University \\ Myanmar
}

\begin{abstract}
Energy consumption is one of the indices in determining the levels of development of a nation. Therefore, availability of energy supply to all sectors of life in any country is crucial for its development. These exists shortage of all kinds of energy, particularly electricity which is badly needed for economic development. Electricity from the sun which is quite abundant in most of the developing countries is used in rural areas to meet basic electricity needs of a rural community. Today's electricity supply in Myanmar is generated by fuel generators and hydroelectric power plants. However, far-flung areas which are away from National Grids cannot enjoy the electricity generated by these sources. Since Myanmar is a land of plentiful sunshine, especially in central and southern regions of the country, the first form of energy- solar energy could hopefully become the final solution to its energy supply problem. The direct conversion of solar energy into electricity using photovoltaic system has been receiving intensive installation not only in developed countries but also in developing countries. It is mainly intended to present solar energy potential and application in Myanmar. In this journal, have discussed the techniques to increase the light gathering ability of a solar panel in the morning and late afternoon by using multiple fixed directed mirrors as a reflector instead of ordinary costly tracking system. In this research have shown the comparison table and figure that depicts how much extra power the panel can add to the system by using mirror with a minimum cost.
\end{abstract}

Keywords - Photovoltaic (PV) system, Electricity supply national grids, Energy, Site condition; Annual radiation, PV Cell, Received Power, Reflector, Tilt Angle.

\section{INTRODUCTION}

The provision of electricity to rural areas derives important social and economic benefits to remove communities throughout the world. The potential for PVpowered rural applications is enormous.

The geographical location of Myanmar is between latitude $9^{\circ} 58^{\prime} \mathrm{N}$ and $28^{\circ} 29^{\prime} \mathrm{N}$ and longitude $92^{\circ} 10^{\prime} \mathrm{E}$ and $101^{\circ} 10^{\prime} \mathrm{E}$. Myanmar has a tropical monsoon climate. The cooler, dry season lasts from November to April and the hotter, wet season from May to September or October. Differences of altitude within the country, and the extent of exposure to the rainy southwest monsoon, are the main factors responsible for differences of climate within Myanmar. The weather is hottest from MarchMay, before the onset of the heaviest rains. Temperatures are cooler in the mountains, but the weather at places below $4000 \mathrm{ft}(1200 \mathrm{~m})$ is hot and tropical in most of the year. In coastal areas, conditions can be uncomfortable because of high humidity. Sunshine is plentiful during the dry season, averaging 7 to 10 hours a day. During the rainy season the weather is cloudier and daily sunshine amounts average only 3 to 4 hours a day. Total area or total square miles of Myanmar is 261228. The radiated heat energy from the sun on to the earth converted to horse power is $469 \times 1011$. Therefore, total approximate horse power on total area of Myanmar is calculated to be $123 \times 10^{10}$, that is the sun's radiated heat power.

The following solar energy technologies can be successfully propagated: solar cookers; solar water heating systems for industrial application; solar distillation units for battery charging; solar photovoltaic systems for water pumping, battery charging, and power supply to children's hospitals for operating vital equipment. Solar air driers can be used for agricultural and industrial products [1].

The objective of this paper is improving the solar energy by using mirror reflection. By using solar tracking the generation of solar energy is less compare to the mirror reflection. So, we can generate more solar energy by using mirror reflection. The improvement of the output power using plane mirror reflector is even higher than that of sun tracking and secondly these reflectors are very cheap and are easily available in market. The average power output during mid day as increased substantially using mirrors, the solar panels equipped with such mirrors can also be utilized for loads/equipments requiring higher power inputs during that period of the day.

\section{Solar Radiation Data of Myanmar}

The MEPE (Myanma Electric Power Enterprise) experimental measurements indicate that irradiation intensity of more than $5 \mathrm{kWh} / \mathrm{m}^{2} /$ day was observed during the dry season. Since the reliability of these systems is paramount, the sizing method used is based on radiation data for the worst month of the year rather than on the average daily irradiation over the year. In addition to ensure system operation even over periods of lower solar radiation than predicted from the average yearly 
values, the sizing often uses data for the worst year in ten [2].

In practical applications, solar cells do not operate under standard conditions. The two most important effects that must be allowed for are due to the variable temperature and irradiance. Temperature has an important effect on the power output from the cell. Irradiance is directly proportional to the short-circuit current of a solar cell [2].

Solar radiation data corresponding to the selected cities in Myanmar is shown in Figure 1.

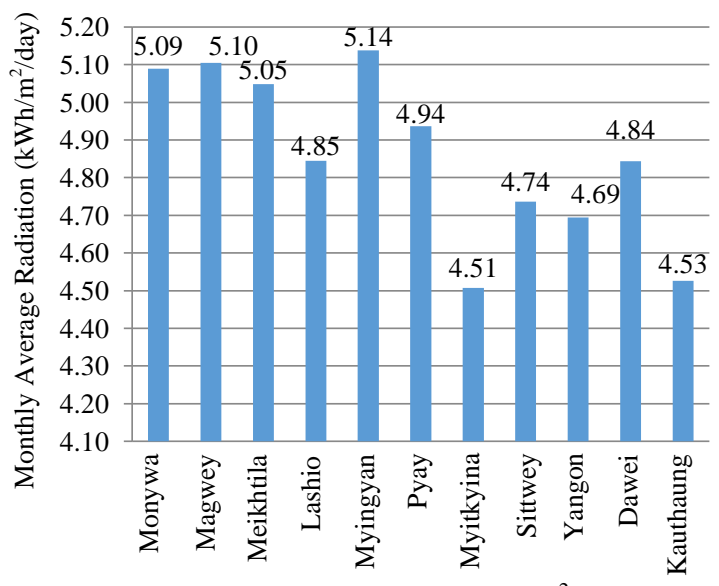

Figure 1 . Monthly average radiation $\left(\mathrm{kwh} / \mathrm{m}^{2} /\right.$ day) records of selected cities [NASA]

\section{RESOURCES OF A SOLAR ENERGY IN SHINTAWKONE VILlage MYANMAR}

Shintawkone village is saturated in Patheingyi township of Mandalay division. It is located between $21^{\circ}$ and $22^{\circ}$ north lattitude and $96^{\circ}$ and $97^{\circ}$ east longitude. For area of an estimation of potential of solar power for regions where are absent Hydrometeorological service, world databases "NASA" can be used. Figure 2 shows monthly average incoming solar radiation on a horizontal surface.

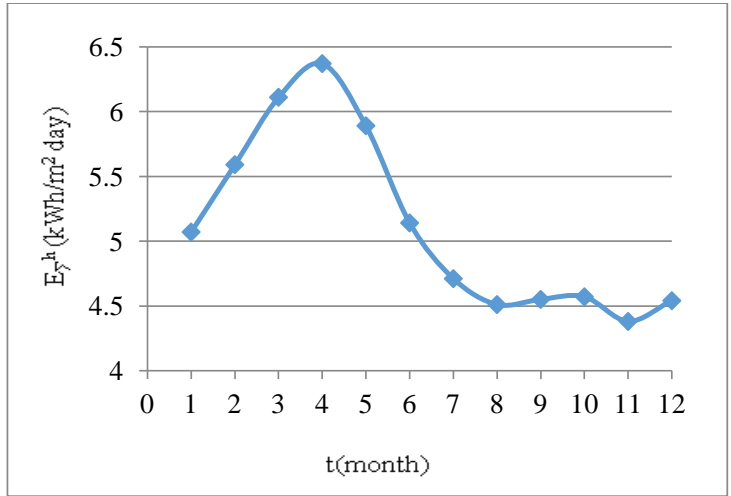

Figure 2. Monthly average incoming solar radiation on a horizontal surface

IV.Calculating Tilt Angle of A ReCEIVING Surface on Arrival Solar RADIATION
The earth revolves around the sun in an elliptical orbit, making one revolution every 365.25 days. The related angles between the sun and the earth are as shown in Figure 3. Table I shows the day numbers for the first day of each month.

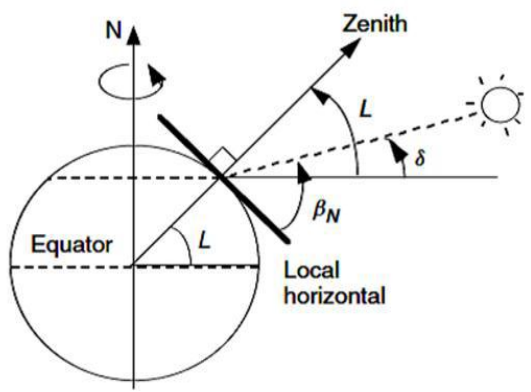

Figure 3. Related angles between the sun and the earth

TABLE I

THE DAy Numbers For THE FIRST DAy OF EACH MONTH

\begin{tabular}{|l|c|}
\hline \multicolumn{1}{|c|}{ Months } & Number (n) \\
\hline January & 1 \\
\hline February & 32 \\
\hline March & 60 \\
\hline April & 91 \\
\hline May & 121 \\
\hline June & 152 \\
\hline July & 182 \\
\hline August & 213 \\
\hline September & 244 \\
\hline October & 274 \\
\hline November & 305 \\
\hline December & 335 \\
\hline
\end{tabular}

\section{A. Tilt Angle of a Receiving Surface on Arrival Solar \\ Radiation}

Array tilt angle for selected location $=90-\beta_{\mathrm{N}}$

$\beta_{\mathrm{N}}=90-\mathrm{L}+\delta$

$\delta=23.45^{\mathrm{O}} \sin \frac{360}{365}(\mathrm{n}-81)$

where,

$\delta=$ the angle between the plane of the equator and a line drawn from the centre of the sun and centre of the earth (varies between extremes of $\pm 23.45^{\circ}$ )

$\mathrm{n}=$ day number for the first day of each months (the spring equinox condition is 81 that is day number)

$\beta_{\mathrm{N}}=$ altitude angle of the sun at noon

$\mathrm{L}=$ latitude angle of the selected location [12]

\section{B. Theorey of Angle between PV and Reflectors}

By mounting reflectors to sides of module, augmentation of radiation on surface of module was takes place. This modified system was able to produce more PV power. The sunlight hitting on the surface of the solar panel can be intensified by the use of parabolic shaped reflectors and flat panel reflectors. Since the manufacturing cost of curved reflectors are higher than that of flat panel reflectors. And since the solar intensifier only works at a certain spot in a certain direction the solar 
panels and the reflectors are in need of a solar tracker system. Although implementing such a system to focus the sunlight on to a smaller area will cause a rise in the temperature and a separate cooling system will also be needed. The intensity of sunlight is very much higher with the reflection of sun light from the mirror than the ordinary sunlight intensity.



Figure 4. Design of PV panel with reflectors as mirror [6]

The amount of produced energy will also depend on the angle between the reflectors and the photovoltaic modules. The concept will utilize two mirrors which will be at fixed angles and they each would reflect additional sunlight on to a half of the solar PV panel. As illustrated in Figure 4 mirrors will be fixed on to the frame leaving a small gap between the solar panel and itself.

\section{A. Angles between Solar PV and Reflectors}

The first step of the design is to add the mirrors to focus additional sunlight on to the solar panel. In this design two mirrors will be used, each reflecting sunlight on to a half of the PV panel. The original area that the sunlight can be collected is only $104 \mathrm{~cm} \times 66 \mathrm{~cm}$. Following are the diagram illustrates the utilization of the mirrors to maximize the solar panel output at a mirror angle of $\theta^{\circ}$. Following are the calculations carried out to find the angles between the PV panel and the mirror and the required length of the mirror, and to select the best angle, considering the cost of the mirror and additional effective width that the mirror creates. The sunlight hitting the additional effective area will be reflected on to a half of the PV panel. The panels are made out of polycrystalline solar cells which have and efficiency of $11-14 \%$ [3].



Figure 5. Illustration for the geometrical calculation [6]

For equation of angle between PV and reflectors:

From Figure 5,

Since $\mathrm{ACC}=\theta, \mathrm{DGC}=90^{\circ}, \mathrm{DG} A=\theta$

Since DGA and EĜF are opposing angles

$\mathrm{EG} F=\theta$

Since EĜF and FĜB are angles of the reflecting sunrays they also have to be equal

Therefore $\mathrm{FGB}=\theta$

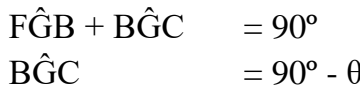

Considering the triangle of $\mathrm{CGB}$;

$\mathrm{BG} \mathrm{C}+\mathrm{GCB}+\mathrm{CBG}=180^{\circ}$

Since BĜC $=\left(90^{\circ}-\theta\right)$,

And GCB $\quad=\left(180^{\circ}-\theta\right)$

$\left(90^{\circ}-\theta\right)+\left(180^{\circ}-\theta\right)+\mathrm{CBG}=180^{\circ}$

$\mathrm{CBG}=\lambda=2 \theta-90^{\circ}$

\section{Calculation Results}

For the research calculated the optimum tile angle of PV solar panel by using Equation 1 to Equation 3 and angles between solar PV and reflectors by using Equation 4 to Equation 5.

\section{A. For Filt Angle of PV Solar Panel}

The optimum tilt angle is a south-facing PV module in Patheingyi Township, Mandalay Division (Latitude 22 degree) at solar noon on March 1. March 1 is the sixtieth day of the year so the solar declination is:

According to Equation: (3)

$$
\delta=23.45^{\mathrm{O}} \sin \frac{360}{365}(60-81)=-8.29^{\circ}
$$

According to Equation: (2)

$$
\beta_{\mathrm{N}}=90^{\circ}-22^{\circ}+\left(-8.29^{\circ}\right)=59.9^{\circ}
$$

According to Equation: (1),

Array tilt angle for selected location $=90-\beta_{\mathrm{N}}$

$$
=30.3^{\mathrm{o}}
$$

Therefore, we placed solar panel towards south at a tilt angle of around $30^{\circ}\left(\approx 30.3^{\circ}\right)$ for selected location.

\section{B. For Angles between Solar PV and Reflectors}

From Figure 5,

And using the law of sins for the same triangle,

$$
\begin{aligned}
\frac{\text { mirror length }(1)}{\sin \left(2 \theta-90^{\circ}\right)} & =\frac{\text { half of the PV panel width }\left(\frac{\mathrm{w}}{2}\right)}{\sin \left(90^{\circ}-\theta\right)} \\
\text { mirror length }(1) & =\frac{-\mathrm{w} \cos (2 \theta)}{2 \cos \theta} \\
\frac{-\cos 2 \theta}{2 \cos \theta} & =\frac{1}{\mathrm{w}}
\end{aligned}
$$




$$
\begin{aligned}
\frac{-2 \cos ^{2} \theta+1}{2 \cos \theta}=\frac{104}{66}=1.576 & \\
-2 \cos ^{2} \theta-3.152 \cos \theta+1 & =0 \\
\cos \theta & =0.2707 \text { or }-1.847 \\
\theta & =74.29^{\circ}
\end{aligned}
$$

According to Equation: (5),

$$
\mathrm{BGC}+\mathrm{GCB}+\mathrm{CBG}=180^{\circ}
$$

From (4) and (5),

$$
\begin{array}{ll}
90^{\circ}-\theta+\mathrm{GCB}+2 \theta-90^{\circ} & =180^{\circ} \\
\mathrm{GCB}+\theta & =180^{\circ} \\
\mathrm{GCB} & =180^{\circ}-\theta \\
& =180^{\circ}-74.29^{\circ}=105.71^{\circ}
\end{array}
$$

Therefore GCB $\left(105.71^{\circ}\right)$ is the angle between reflectors and solar panel. For the experiment used a solar panel, which has the following features in Table II.

TABLE II

SPECIFICATIONS OF POLY-CRYSTALLINE SOLAR PANEL

\begin{tabular}{|l|c|c|}
\hline \multicolumn{2}{|c|}{ Module Type } & SYM 90P \\
\hline Cell Material & $\mathrm{P}_{{ }_{\max }}$ & Poly Crystalline \\
\hline Maximum Power & $90 \mathrm{~W}$ \\
\hline Maximum Power Voltage & $\mathrm{V}_{\mathrm{p} \max }$ & $18.37 \mathrm{~V}$ \\
\hline Maximum Power Current & $\mathrm{I}_{\mathrm{pmax}}$ & $4.9 \mathrm{~A}$ \\
\hline Open Circuit Voltage & $\mathrm{V}_{\mathrm{oc}}$ & $22.05 \mathrm{~V}$ \\
\hline Short Circuit Current & $\mathrm{I}_{\mathrm{sc}}$ & $5.15 \mathrm{~A}$ \\
\hline
\end{tabular}

\section{Mathematical Model OF PV SOlaR PANEL USING MIRROR AS REFLECTOR AND WITHOUT USING REFLECTOR}

Solar panel towards north-south at a tilt angle of around $30^{\circ}\left(\approx 30.3^{\circ}\right)$ and taken data by using multi-meter for a $2^{\text {th }}$ in July 2018 in the same weather and temperature. We used both mirror as reflector and without using reflector to concentrate sunlight onto the panel from the morning to the late afternoon. Using multimeter took both open circuit voltage and short circuit current and then calculates the power received by the panel.

$$
\text { Power }(\mathrm{W})=\text { Open Circuit Voltage } \times \text { Short Circuit Current }
$$

These values from 7.00 AM to 5.00 PM. Panels are observed that in the early morning and late afternoon the panel gives minimum power both by using reflector and without reflector as shown in Figure 6 and Figure 7. Table III shows the variation of current, voltage and power of a photovoltaic solar panel using mirror as reflector and without using reflector.



Figure 6. A solar PV panel without using reflector

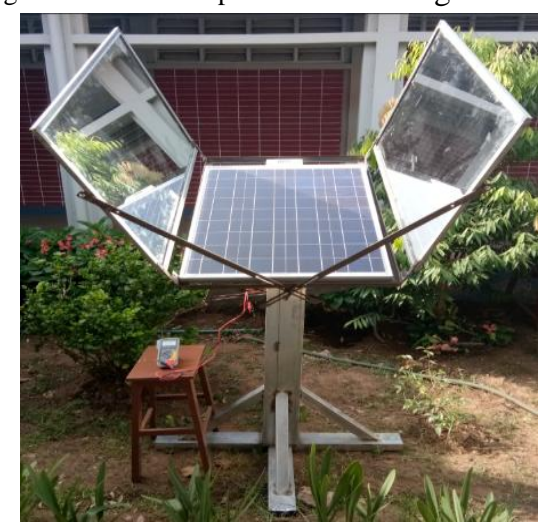

Figure 7. A solar PV panel using mirror as reflectors

TABLE III

Received Data of a PV SOlar Panel using MirRor as REFLECTOR AND WITHOUT USING REFLECTOR

\begin{tabular}{|c|c|c|c|c|c|r|}
\hline Time & \multicolumn{2}{|c|}{$\begin{array}{c}\text { Open } \\
\text { circuit } \\
\text { voltage(V) }\end{array}$} & \multicolumn{2}{c|}{$\begin{array}{c}\text { Short circuit } \\
\text { current (A) }\end{array}$} & \multicolumn{2}{c|}{$\begin{array}{c}\text { No load output } \\
\text { Power (W) }\end{array}$} \\
\hline & $\begin{array}{c}\text { No } \\
\text { Mirror }\end{array}$ & $\begin{array}{c}\text { Using } \\
\text { Mirror }\end{array}$ & $\begin{array}{c}\text { No } \\
\text { Mirror }\end{array}$ & $\begin{array}{c}\text { Using } \\
\text { Mirror }\end{array}$ & $\begin{array}{c}\text { No } \\
\text { Mirror }\end{array}$ & $\begin{array}{c}\text { Using } \\
\text { Mirror }\end{array}$ \\
\hline 7:00 AM & 1.65 & 1.02 & 1.81 & 1.85 & 1.68 & 3.55 \\
\hline 7:30 AM & 5.63 & 1.06 & 15.59 & 1.87 & 5.97 & 29.15 \\
\hline 8:00 AM & 13.38 & 1.78 & 17.16 & 2.06 & 23.82 & 35.35 \\
\hline 8:30 AM & 16.53 & 1.96 & 13.32 & 3.59 & 32.40 & 47.82 \\
\hline 9:00 AM & 16.67 & 2.12 & 13.65 & 3.35 & 35.34 & 45.73 \\
\hline 9:30 AM & 10.98 & 3.22 & 14.05 & 3.67 & 35.36 & 51.56 \\
\hline 10:00 AM & 13.46 & 3.46 & 14.41 & 3.71 & 46.57 & 53.46 \\
\hline 10:30 AM & 13.66 & 3.59 & 14.36 & 3.75 & 49.04 & 53.85 \\
\hline 11:00 AM & 14.12 & 3.65 & 14.33 & 3.78 & 51.54 & 54.17 \\
\hline 11:30 AM & 14.15 & 3.65 & 14.21 & 3.68 & 51.65 & 52.29 \\
\hline 12:00 AM & 14.21 & 3.68 & 14.75 & 3.72 & 52.29 & 54.87 \\
\hline 12:30 PM & 14.08 & 3.70 & 14.09 & 3.59 & 51.91 & 51.99 \\
\hline 1:00 PM & 13.32 & 3.58 & 14.16 & 3.68 & 47.69 & 52.11 \\
\hline 1:30 PM & 12.51 & 3.42 & 14.06 & 3.6 & 42.78 & 50.62 \\
\hline 2:00 PM & 12.78 & 3.19 & 14.26 & 3.64 & 40.77 & 51.91 \\
\hline 2:30 PM & 16.6 & 1.98 & 12.13 & 3.24 & 32.87 & 39.30 \\
\hline 3:00 PM & 16.22 & 1.96 & 12.7 & 3.46 & 31.79 & 43.94 \\
\hline 3:30 PM & 11.76 & 1.64 & 11.59 & 3.26 & 19.29 & 37.78 \\
\hline 4:00 PM & 8.87 & 1.32 & 11.6 & 3.29 & 11.71 & 38.16 \\
\hline 4:30 PM & 5.62 & 1 & 16.38 & 2.01 & 5.62 & 32.92 \\
\hline 5:00 PM & 2.14 & 0.66 & 12.74 & 1.82 & 1.41 & 23.19 \\
\hline & & Total & & & 651.56 & 895.97 \\
\hline
\end{tabular}




\section{COMPARISON OF PV SOLAR PANEL USING MIRROR AS REFLECTOR AND WITHOUT USING REFLECTOR RESULTS}

The solar panel received maximum $52.29 \mathrm{~W}$ and minimum $1.68 \mathrm{~W}$ using without reflectors and maximum 54.87 $\mathrm{W}$ and minimum $3.55 \mathrm{~W}$ using reflectors.

Comparison efficiency of PV solar panel using mirror as reflector and without reflector are

$$
\begin{aligned}
\eta & =\frac{\sum \mathrm{p}_{2}-\sum \mathrm{p}_{1}}{\sum \mathrm{p}_{1}} \times 100 \% \\
\eta & =\frac{895.97-651.56}{651.56} \times 100 \% \\
\eta & =37.51 \%
\end{aligned}
$$

In this research that solar panel using mirror as reflector gives some extra power in the early morning and it is gradually increased at around $8.30 \mathrm{am}$. At that time panel received additional using mirror as a reflector. If we consider 10 hours' period from 7.00 AM to 5.00 PM, the panel without using reflector receives average power of $52.29 \mathrm{~W}$ which is $72.11 \%$ of the panel power. Whereas using reflector (mirror) the panel receives average power of $54.87 \mathrm{~W}$ which is $64.02 \%$ of the panel power. Therefore, the panel receives extra $37.51 \%$ power using mirror as a reflector. In Figure 8, the panel receives $72.11 \%$ without using reflector and $64.02 \%$ using reflector (mirror) of the panel capacity.

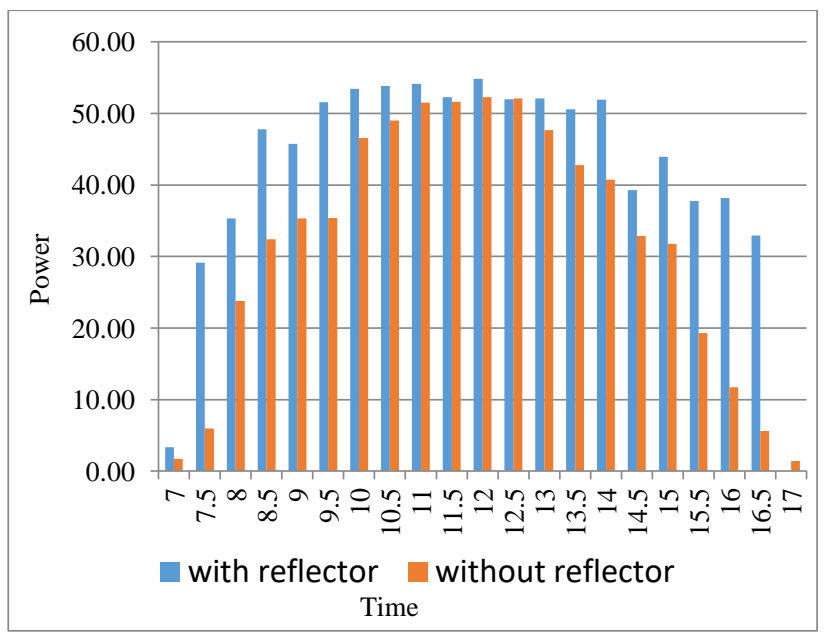

Figure 8. Receive power comparison using reflector (mirror) and without using reflector

\section{Conclusions}

From the research of the received power comparison using reflector and without using reflector; we can conclude that reflector plays a vital role in a solar power system. Photovoltaic solar panel using reflectors increases received power efficiency all day long specially in the morning and late afternoon. Using this technique the rural people can efficiently use their solar panel all the year.

\section{ACKNOWLEDGMENT}

The author greatly expresses to his thanks to all persons whom will concern to support in preparing this paper.

\section{REFERENCES}

[1] [1] S.K. Sharma, "Alternate Energy Utilization in Myanmar," A Unicef

[2] Myanmar Publication, March, 1992,University of Southampton, UK.

[3] Himangshu Bhowmik and Ruhul Amin, Efficiency Improvement of Flat Plate Solar Collector Using Reflector, Dhaka University of Engineering \& Technology, Department of Mechanical Engineering, Gazipur, Bangladesh, 2017.

[4] GDM pathmika and MV Gamage, Efficiency Improvement of a Typical Solar Panel with the Use of Reflectors, Department of Mechanical Engineering, Faulty of Engineering, University of Sunderland, UKmihiran.g@sliit.edu.lk, 2016.

[5] Ionel L.Alboteanu, Cornelia A. Bulucea and Sonia Degeratu, Estimating Solar Irradiation Absorbed by Photovoltaic Panels with Low Concentration Located in Craiova, Romania, Department of Electromechanics, Environment and Industrial Informatics, Faculty of Electrical Engineering, University of Craiova 200440, Romania, 2015.

[6] S Ahmed, More Efficient use of Photovoltaic Solar Panel Using Multiple Fixed Directed Mirrors or Aluminium Foils Instead of Solar Trackers in Rural Perspective of Bangladesh, International Journal of Scientific and Technology Research, 2014, 3(4).

[7] V.N. Palasker and S.P.Deshmukh, Design and Performance Analysis of Reflectors Attached to Commercial PV Module, Veermata Jijabai Technological Institute Matunga Mumbai, India, 2014.

[8] Potuganti Prudhvi and Ponnapalli Chaitanya Sai, Efficiency Improvement of Solar PV Panels Using Active Cooling, Dept of EEE and Department of Mechanical engineering at NIT Warangal, 2012.

[9] G. C. Jain, Development and manufacture of photovoltaic system in developing countries, National physics laboratory, New Delhi, 1981.

[10] J. Rizk, and Y. Chaiko, - Solar Tracking System: More Efficient Use of Solar Panels,॥ World Academy of Science, Engineering and Technology 41 (2008)

[11] Faisal Ahammed, Dilder Ahmed Taufiq, -Applications of Solar PV On Rural Development in Bangladesh,\| Journal of Rural Community Development 3 (2008) 93-103 
International Journal of Science and Engineering Applications

Volume 7-Issue 08,193-198, 2018, ISSN:-2319-7560

[12] Shakir-ul-haque Khan, Towfiq-ur-Rahman, and Shahadat Hossain, -A Brief Study of the Prospect of Solar Energy in Generation of Electricity in Bangladesh,\| Journal of Selected Areas in Renewable and Sustainable Energy (JRSE), June Edition, 2012 